\title{
La relación obligatoria como proceso en la construcción del paradigma de los deberes generales de conducta y sus consecuencias
}

\author{
Theobligatoryrelationship as a process in \\ buildingtheparadigm of the general rules of conduct \\ and itsconsequences
}

Marcos Ehrhardt Júnior*

\section{Resumen}

El artículo se ocupa de la relación jurídica obligatoria desde la perspectiva de la metodología civil -constitucional, frente a la cuestión de la complejidad y la evolución dogmática de las normas generales de conducta. Concluye que el concepto clásico de relación obligatoria se reveló inadecuado e insuficiente para tutelar todas las vicisitudes inherentes a la visión solidarista de la relación obligacional, que ya no se limita al resultado de la suma de deuda o crédito, debiendo abandonar dicha posición estática para que el vínculo obligatorio sea visto como un proceso de cooperación dirigido a determinado fin.

Palabras-clave: Relación jurídica obligacional. Relación obligacional como proceso. Deberes generales de conducta.

\section{Abstract}

The article deals with the binding legal relationship from the perspective of civil-constitutional methods, addressing the issue of complexity and dogmatic evolution of the general rules of conduct. Concludes that the classical concept of mandatory relationship was revealed inadequate and insufficient to protect all

Advogado. Doutor em Direito pela Universidade Federal de Pernambuco (UFPE). Professor de Direito Civil da Universidade Federal de Alagoas (UFAL). Traducción de César E. Moreno More,Asistente de Docencia en la Universidad Nacional Mayor de San Marcos, Adjunto de Docencia en la Pontificia Universidad Católica del Perú, Candidato a la Maestría con mención en Derecho Civil y Comercial por la Universidad Nacional Mayor de San Marcos. Maceió - Alagoas - Brasil. E-mail: contato@marcosehrhardt.com.br. 
the vicissitudes inherent in the solidarity vision of obligational relationship, which is no longer limited to the result of the sum of debt or credit, must leave this static position for the obligatory link is seen as a process of cooperation aimed at any particular purpose.

Keywords: Obligational legal relationship. Obligational relationship as a process. General duties of conduct.

\section{Introducción}

Partiendo del análisis del derecho desde su origen en el fenómeno social, de la interacción entre los sujetos, se observa a la relación jurídica como una de las categorías más importantes de la teoría general del derecho. Entre los tratadistas tradicionales existe cierta uniformidad en la delimitación del concepto de relación jurídica obligacional, muy bien caracterizado en las lecciones de Arnaldo Rizzardo (2006, p.4), quien define a la obligación como una relación en virtud de la cual «alguien debe cumplir determinada prestación en favor de otro. O someterse el deudor a una determinada prestación a favor del acreedonı.

Para SílvioRodrigues (2002, p.34), la obligación es el vínculo jurídico en virtud del cual alguien (sujeto pasivo) se propone dar, hacer o no hacer algo (objeto), a favor de otro (sujeto activo). En el mismo sentido, CaioMário da Silva Pereira (2009, p.3-4) observa que «el recurso a la etimología es de mucha ayuda: obligación, del latín ob + ligatio, contiene una idea de vinculación, de ligamen, de limitación de la libertad de acción, en beneficio de una persona determinada o determinable».

Todos los autores citados remarcan en sus escritos el carácter transitorio y económico de la relación, desde el momento en que su cumplimiento es garantizado mediante el patrimonio del deudor, razón por la cual Orlando Gomes (2004, p.17) sostenía que, considerada en su conjunto, la relación obligatoria es

un vínculo jurídico entre dos partes, en virtud del cual una de ellas queda sometida a satisfacer una prestación 
patrimonial de interés de la otra, que puede exigirla, si no es cumplida espontáneamente, mediante la agresión al patrimonio del deudor

Bajo esta perspectiva, estudiar la relación obligatoria, a partir de su regulación en el Código Civil Brasileño [en adelante Cód. Civ. Br.], sólo significa analizar sus elementos constitutivos, razón por la cual se distinguen (a) el elemento subjetivo, vale decir, los sujetos de la relación jurídica (sujeto activo o acreedor y sujeto pasivo o deudor); (b) el elemento objetivo o material, relativo a su objetivo, que puede ser reducido en una prestación de hacer, no hacer o de dar, y (c) el vínculo jurídico, también denominado elemento inmaterial, abstracto o espiritual, que sería precisamente el elemento que otorga al acreedor el derecho de exigir del deudor el cumplimiento de la obligación. (GONÇALVES, 2009, p.23).

\section{La relación jurídica obligacional desde su perspectiva tradicional}

La relación jurídica obligacional, en sentido amplio, presenta una faz doble: es un elemento activo del patrimonio del acreedor y un elemento pasivo del patrimonio del deudor. Lo que permite afirma que «al derecho corresponde el deber, que tiene por objeto la prestación». (LÔBO, 2011, p.28-29). Por otro lado, en sentido estricto, se concibe a la obligación como el deber (deuda) que puede ser exigido por el acreedor.

Analizando la relación jurídica obligacional desde la óptica de la teoría del hecho jurídico, se puede afirmar que el derecho subjetivo es aquel que resulta de la incidencia de la norma con la formación del hecho jurídico, que pone a un sujeto en relación de ventaja respecto a otro sujeto que, de forma correlativa, tiene un deber subjetivo.(CATÃO, 2002, online). De esta forma, surge un derecho subjetivo cuando, por ejemplo, se celebra determinado negocio jurídico que permite al sujeto satisfacer un interés jurídicamente protegido. Normalmente hay, en el 
contenido de eficacia de la relación jurídica, además del derecho, la pretensión de un sujeto, que corresponde a la obligación del otro.

En otras palabras, en el derecho obligatorio el acreedor (sujeto activo) es aquel que tiene la facultad, reconocida por el sistema jurídico, de exigir del deudor (sujeto pasivo) una prestación, esto es, la realización de una conducta, que se manifiesta por el ejercicio de una obligación de dar, hacer o no hacer.

Dicho de otra forma: «la pretensión es la posición subjetiva de poder exigir de otro alguna prestación positiva o negativa»;1(PONTES DE MIRANDA,1984, p. 52), por lo tanto, esto quiere decir la exigibilidad, vale decir, la facultad de cobrar de otro la satisfacción de un interés jurídicamente reconocido y protegido por el ordenamiento.

Pontes de Miranda(1984, p. 12), preocupado por la precisión de los conceptos, sostiene que "quien debe, está en posición de deber o tener que cumplir. Puede no estar obligado a ello. De modo que tiene el deber, y no tiene obligación. [...] Crédito sin pretensión es un crédito mutilado [...] El crédito existe, sin embargo no se puede exigir".

En una relación jurídica obligatoria, no puede existir obligación sin deuda (deber), la cual, a su vez, no puede ser confundida con la prestación, porque esta es el objeto de aquella. Debemos observar que el objeto de la prestación no es la cosa en sí misma considerada, sino una acción u omisión del deudor, esto es, un dar, hacer o no hacer.

De la misma forma, y considerando los fines del presente trabajo, es necesario distinguir deuda de responsabilidad ${ }^{2}$. Concebimos a la deuda (débito, deber) como el elemento correlativo del derecho del acreedor. De esta forma, el deudor puede, en virtud de la obligación, responder con su patrimonio o parte de él, ya que la responsabilidad

Razón por la cual Marcos Bernades de Mello (2007, p. 183) afirma que la pretensión «constituye el grado de exigibilidad del derecho (subjetivo) y la obligación de sujeción al cumplimiento».

2 El tema de la distinción entre deuda y responsabilidad es retratado frecuentemente utilizando términos sinónimos. Hay quien prefiere hablar de schuld, debitum, duty o devoir para referirse a la deuda, en tanto la noción de responsabilidad es presentada bajo la denominación de haftung, obligatio, liability o engagement. 
no es personal, afectando sólo el patrimonio del sujeto pasivo -y no su libertad-para la satisfacción de la deuda, siempre que no se comprometa el mínimo necesario para la existencia de la persona humana ${ }^{3}$.

Sin embargo, la unidad del derecho de las obligaciones ya no se encuentra arraigada exclusivamente a los códigos civiles, sino también al conjunto de principios y reglas establecidas en la Constitución, en torno a los cuales gravitan los microsistemas jurídicos que tratan de las materias vinculadas a él.(LÔBO,2011, p.18)

Por esta razón debemos considerar el texto constitucional como la cúspide conformadora de la elaboración y aplicación de la legislación civil al propiciar la unidad hermenéutica ${ }^{4}$ en relación a espacios hasta entonces considerados distintos y, a veces, contrapuestos, lo que lleva a Paulo LuizNettoLôbo(2011, p.18) a las siguientes conclusiones:

De la Constitución brasileña se obtiene, a causa de los valores incorporados en sus normas, que, en el plano general de las obligaciones convencionales, el paradigma liberal de prevalencia del interés del acreedor y del antagonismo fue sustituido por el equilibrio de derechos y deberes entre acreedor y deudor, no sólo en la dimensión formal de tradición de los juristas, sino, sobre todo, en la dimensión de la igualdad o equivalencia material, fundado en el principio de solidaridad social.

3 Como bien observa Luiz Edson Fachin (2006, p. 280-1), «el mínimo no es referido en función a la cantidad, y puede estarlo mucho más allá del número o de la cifra medible. Tal mínimo constituye un valor y no una medición, [...] no es menos ni ínfimo. Es un concepto apto para la construcción de lo razonable y de lo justo al caso concreto, abierto, plural y propenso al mundo contemporáneo».

4 «Se hace evidente que ya no se puede concebir, a la luz de dichas premisas, que la relación jurídica sea representada por una ecuación lineal. Por el contrario, ahora se la concibe como un haz de obligaciones que se proyectan recíprocamente entre las partes que componen la relación jurídica, en un contexto de colaboración y también con vinculaciones externas en consideración de la necesaria obediencia a la función social del contrato» (CATALAN, 2010, p. 113). 
Considerando lo afirmado en los parágrafos anteriores, podemos concluir que el concepto clásico de relación obligatoria ${ }^{5}$ se reveló inadecuado e insuficiente para tutelar todas las vicisitudes inherentes a la visión solidarista de la relación obligacional, que ya no se limita al resultado de la suma de deuda o crédito, debiendo abandonar dicha posición estática ${ }^{6}$ para que el vínculo obligatorio sea visto como un proceso de cooperación dirigido a determinado fin.

No se trata de que las partes se liberen de su libertad de acción, sino de conformar su comportamiento con la dimensión social, (NANNI, 2008, p.283-321) ya que a pesar de que sufran modificaciones puntuales en el proceso, no hay una pérdida de su «identidad de base». (BECKER, 2010, p.353-372). Es dentro de esta perspectiva que se plantea «la idea de que el vínculo obligacional comprende, además de un débito y de un crédito, diversos elementos jurídicos, susceptibles de un tratamiento diferenciado y dotados de un sentido global que los trasciende», tal como veremos en el siguiente acápite.

\section{La relación jurídica obligacional como proceso}

Como hemos visto, tradicionalmente la relación jurídica obligacional siempre fue concebida como una estructura unitaria que se limitaba

5 Cristiano Chaves de Farias y Nelson Rosenvald(2009, p. 11) presentan una buena síntesis de la uniformidad conceptual de la relación jurídica obligatoria clásica, a saber: a) carácter transitorio (además porque no puede haber una relación obligatoria perpetua, lo que implicaría, como se puede extraer de su concepto, una verdadera servidumbre humana); b) vínculo jurídico entre las partes (a través del cual la parte interesada puede exigir de la otra, coercitivamente, el cumplimiento); c) carácter patrimonial (ya que sólo el patrimonio del deudor puede ser afectado, una vez descartada su responsabilidad personal); d) prestación positiva o negativa (puede ser una conducta consistente en un dar, hacer o no hacer). En defensa de una relectura de la estructura obligacional clásica, a la luz del principio de la buena fe objetiva (2005, p. 75-7).

6 Gustavo Tepedino, Heloísa Barbosa y Maria Celina Bodin de Moraes(2004, p.492) señalan que «al mismo tiempo en que las escuelas de derecho civil contemporáneo aclaman la historicidad y la relatividad de sus instituciones, la Teoría general de la Obligaciones continúa siendo tratada, difusamente, de la misma forma acrítica con que se afrontó el tema en la codificación anterior. Las obligaciones se constituirian, según la concepción tradicional, en la más perfecta expresión de la racionalidad técnica del derecho civil: una regulación perenne, definitiva» Tal como veremos a continuación, dicha tendencia no toma en consideración las necesidades de la contemporaneidad. 
a regular el derecho del acreedor al cumplimiento de la prestación, contrapuesto al deber del cumplimiento de la prestación impuesto al deudor, concepción que, en principio, no comprende la posibilidad de percibir en alguno de los partícipes de la relación obligatoria la posición simultánea de acreedor y deudor.

Defendiendo el tratamiento de la relación obligatoria como un todo y resaltando con dicha afirmación toda la complejidad intraobligacional, Clóvis de Couto e Silva (2006, p.20) señala que «aunque se haya cumplido el deber principal, la relación jurídica puede subsistir como fundamento de la adquisición (deber de garantía), o a causa de otro deber secundario independiente».

Para el citado autor, los deberes accesorios de conducta estarían divididos en deberes dependientes e independientes, siendo la razón de la diferenciación la verificación de que algunos de ellos «son susceptibles de sobrepasar el plazo de la obligación principal, teniendo así vida propia. A causa de esta particularidad, pueden ser accionados independientemente de la prestación principal».(COUTO E SILVA, 2006, p.96).

Dentro de esta perspectiva, los actores de la relación jurídica obligatoria deben buscar el cumplimiento satisfactorio, que deriva de múltiples facultades y situaciones que se despliegan de modo dinámico a los largo de todo el iter de la relación jurídica obligatoria, que pasa a ser vista como un conjunto complejo de fases direccionadas a un fin que no se satisface sólo con el cumplimiento del deber de prestar. (HAICAL, 2011, p.487).

Partiendo de dicha concepción, se analiza el cumplimiento contractual por su función económico-social y no sólo por el objeto principal de la obligación, teniendo en cuenta que a partir del contacto social surgen deberes relacionados a la esfera jurídica de otro contratante, las mismas que varían de conformidad a las peculiaridades de la situación, razón por la cual:

Los deberes accesorios no consisten, por lo tanto, en 
elementos de la relación contractual existentes ab initio, en numerus clausus y con un contenido fijo. Su concretización depende de la verificación de presupuestos variables que, a la luz del fin del contrato, adquieren dicha eficacia. Y no sólo su surgimiento: también su contenido interno, intensidad y duración dependen de las circunstancias actuales. De cierta forma, se puede decir que existen, potencialmente, desde el inicio y son actualizados a medida que se van verificando las situaciones que ponen en peligro la consecución del interés en el contrato. Por lo tanto, su establecimiento sólo es posible en determinado momento temporal y su existencia prescinde de la hipótesis de su violación, al extinguirse con su cumplimiento o con su superación a través de una modificación de las circunstancias que determinaron su surgimiento, lo que los deja sin objeto.(BECKER, 2010, p. 353-372)

Clóvis de Couto e Silva (2006, p.64) enseña que dichos deberes generales son independientes de la voluntad de los implicados y surgen del contacto social que se instaura en las tratativas, antes de la incidencia de una norma jurídica que juridice el negocio celebrado entre las partes.

Entonces, se debe analizar la relación jurídica obligatoria en su totalidad, observándola como un conjunto completo de fases dirigidas a una finalidad, que aunque mantenga como médula el deber de prestar, (HAICAL, 2011, p.488) no alcanzará su finalidad sólo mediante el cumplimiento de dicho deber, pues se pasa a considerar la existencia de otros deberes exigibles de los actores de dicha relación, los cuales también tendrán que ser observados para que la satisfacción sea completa.

En esta transición de un paradigma estático a un modelo dinámico de la relación obligatoria, es necesario una relectura del régimen del derecho obligatorio que no puede ser considerado como mero estatuto del acreedor, pues, como señala Pietro Perlingeri (2007, p.212) , la obligación ya no se identifica con el derecho o los derechos del acreedor, ya que cada vez con mayor frecuencia se configura como una relación de cooperación a través de la cual el sujeto activo necesita adoptar una 
postura de colaboración para el cumplimiento, de manera que se supere toda concepción de sumisión, para permitir así que el sujeto pasivo se vea liberado del vínculo. (FARIAS, 2009, p.13). El referido autor continúa sosteniendo que:

La incidencia constitucional se realiza de diversas formas: no sólo en la identificación de los contenidos de las cláusulas generales, como la diligencia, la buena fe, la lealtad, el estado de necesidad, etc., sino principalmente, en la relectura orientada axiológicamente de todo el régimen en el que consiste la relación y, en especial, en el control de valor de los órdenes de intereses representados por el título [...] y en la relevancia de que la peculiaridad de este último tiene condiciones de producir en la estructura formal de la relación.(PERLINGIERI,2007, p. 211).

Es por ello que corresponde analizar el plano de la eficacia ${ }^{7}$ de la relación jurídica obligatoria en toda su complejidad, identificando derechos y deberes primarios, secundarios o laterales.

\section{La complejidad y la evolución dogmática de los deberes laterales de conducta en el plano de la eficacia de la relación jurídica obligacional}

Los derechos y deberes primarios de la relación jurídica obligatoria constituyen su médula, en la medida en que están relacionados al núcleo de la satisfacción de los sujetos de determinada relación jurídica,

\footnotetext{
Marcos Bernardes de Mello (2003, p.171) aclara que «todo lo que ocurre en el mundo jurídico, sin excepción, es consecuencia (eficacia) del hecho jurídico. En este mundo, nada ocurre sin que exista un hecho jurídico en su origen. Partiendo de esta premissa, téngase por evidencia que la relación jurídica es, exclusivamente, efecto del hecho jurídico, siendo el concepto perteneciente al plano de la eficacia» (p. 169). El autor destaca cuatro princípios fundamentales que rigen las relaciones jurídicas, advirtiendo que la (1) intersubjetividad, (2) la esencialidad del objeto y la (3) correlatividad de derecho y deber, pretensión y obligación, acción y situación de accionado y excepción y situación de excepcionado, son esenciales ya que su ausencia comprometería la propia existencia de la relación jurídica. Mientras tanto el (4) principio de la coextensión de derecho, pretensión y acción no sería esencial, porque puede sufrir excepciones sin afectar la existencia de la relación jurídica.
} 
permitiendo la distinción correcta entre los tipos contractuales. A su lado, gravitando en una relación de complementariedad, se encuentran los derechos y deberes secundarios ${ }^{8}$, de carácter accesorio a la prestación principal. Estos ejercen una función de garantía de la plena realización de los intereses de los actores de la relación obligatoria (interés en el cumplimiento).

Mientras tanto, como hemos afirmado anteriormente, la relación obligatoria vista como un proceso exige la observancia de otra especie de deberes que no están relacionados únicamente al estricto cumplimiento de la prestación. Se trata de los deberes laterales o accesorios, en ocasiones denominados en la doctrina brasileña como colaterales(TOMASETTI JUNIOR, 1995, p.16-17)instrumentales(SAVI, 2005, p.476)o fiduciarios(NORONHA, 2004, p.79-81).

El desarrollo de dicha categoría se debe a los trabajos de HermannStaub y Heinrich Stoll, quienes afrontaron las dificultades que existían en la aplicación del código civil alemán antes de la ley de modernización del 2000. De la mano de estos juristas, surgió la teoría de la violación positiva del contrato, relacionada a los deberes de cumplimiento, y el desarrollo de los deberes de protección en la relación jurídica obligatoria, influenciando fuertemente la construcción doctrinaria y jurisprudencial en la dirección de la ampliación del concepto de cumplimiento obligacional.

El tratamiento dogmático de los deberes laterales de conducta sobrepasó la mera exigencia de protección de los actores y de su patrimonio para exigir un comportamiento dirigido hacia la obtención de la plena satisfacción de la obligación, comprendiendo deberes de

8 Hay quien divide los deberes secundarios en diversas especies, diferenciando los deberes accesorios de la prestación principal (función de garantía) de aquellos deberes con prestación autónoma (relativos a una falta del propio programa obligacional), que incluso se subdividen en deberes sucedáneos (indemnización por daños y perjuicios en virtud de incumplimiento absoluto) o deberes coexistenciales a la prestación principal (indemnización en virtud de la mora). Por lo menos, en la experiencia brasileña, elevar la clasificación de los deberes de la relación obligatoria a ese nivel de refinamiento causaría más perjuicios que ventajas, sin atribuir ninguna utilidad, en el campo pragmático, a la adopción de dichas subdivisiones (HAICAL,2011, p. 491-492). 
información (esclarecimiento) y de lealtad, en cuyo fundamento está la buena fe.

El contenido de los deberes laterales de protección está relacionado a la exigencia de que las partes eviten causar daños mutuos a sus esferas jurídicas. Por su parte, los deberes laterales de esclarecimiento obligan a las partes a informarse mutuamente de todos los aspectos correspondientes al vínculo, a los cuales deben sumarse los deberes de lealtad, imponiéndoles la abstención de todo comportamiento que pueda desequilibrar las prestaciones, así como la adopción de deberes de actuación positiva para garantizar el mismo objetivo. (MENEZES, 2011, p. 604-607).

Un punto importante para la mejor comprensión del problema aquí planteado es la distinción entre deberes de prestación y deberes de protección, en especial cuando se considera que los efectos jurídicos de dichos deberes no se restringen sólo a los actores de la relación obligatoria y en ocasiones son extendidos a terceros ${ }^{9}$.

A pesar de que el contrato hubiese sido celebrado sin ninguna estipulación a favor de tercero (pretensión a la prestación), se reconoce al sujeto extraño a la relación obligacional, una pretensión a la protección. Como señala Gustavo Luís da Cruz Haical (2011, p.498), «el deber de prestación se fundamenta en la existencia de la relación obligatoria establecida, teniendo su soporte fáctico descrito en la ley o en los usos del tráfico cuando estos sean modelos jurídicos. En cambio, los deberes

9 Seguro de vida. Plazo de tolerancia. Suicidio no premeditado. Principio de buena fe. Aplicabilidad de las súmulas 105/STF y 61/STJ. El planeamiento del acto suicida, para fines de fraude contra el seguro, nunca podrá ser presumido. La buena fe siempre se presume, mientras que la mala fe debe ser comprobada. A pesar de la nueva previsión legal, establecida por el art. 798 del Cód. Civ. Br. de 2002, las súmulas 105/STF y 61/STJ siguen siendo aplicables a las hipótesis en las que el asegurado comete suicidio. La interpretación literal y absoluta de la norma contenida en el art. 798 del Cód. Civ. Br. de 2002 no toma en consideración importantes aspectos de orden público, entre los cuales se incluyen la necesidad de protección del beneficiario del contrato de seguro de vida celebrado de conformidad con los principios de la buena fe objetiva y lealtad contractual (Recurso Especial 959.618/RS, Ponente Ministro SIDNEI BENETI, Ponente de la decisión Ministra Nancy Andrighi, Terceira Turma, fecha de decisión 7/12/2010, Diario de justicia electrónico 20/6/2011). 
laterales, no poseen un contenido predeterminado, pues derivan de la buena fe objetiva» ${ }^{10}$.

En relación a la intensidad de la exigibilidad de los deberes que componen la relación jurídica obligatoria concebida como un proceso, se deben notar diferencias marcadas entre los deberes de prestación (principales y secundarios) y los deberes laterales de protección, información y lealtad. Estos no se encuentran preestablecidos en ninguna de las especies contractuales, al contrario de los deberes principales, que, como hemos vistos, definen la naturaleza y estructura del vínculo jurídico entre las partes.

Pero ello no es todo. Los deberes laterales son exigibles durante todo el iter de la relación obligatoria compleja, desde la fase precontractual, cuando la relación jurídica entablada entre las partes y fundamentada en el contacto social aún no presente deberes de prestación, basándose principalmente en la confianza depositada por los actores en la conducta leal y honesta del otro; pasando por la fase de ejecución y desarrollo del negocio, y subsistiendo incluso después de que esta se extingue por el cumplimiento de los deberes de prestación, ya que es exigible que en la fase postcontractual los actores aseguren la plena utilidad de los derechos adquiridos.

Esta perspectiva deber tomar en consideración que la complejidad de la relación jurídica obligatoria no se resume a la mera suma de sus elementos parciales ${ }^{11}$. Dicho de otra forma: la relación obligatoria

10 Al tratar de los contratos con eficacia protectora para terceros, Pontes de Miranda (1984, § 3.165, p. 266$)$ dejaba claro su naturaleza jurídica de negocios sin pretensión a la prestación, aunque se reconocía que el tercero era titular de las pretensiones de diligencia o protección. Él remarcaba que la extensión sería de la «eficacia protectora».

11 Para MárioLuiz Delgado Régis, «la obligación debe ser vista no sólo por la suma de sus elementos constitutivos, sino como un proceso, una serie de actos relacionados entre sí, que se enlazan y convergen en dirección a la satisfacción de los intereses recíprocos del acreedor (de recibir) y del deudor (de pagar) terminando con el cumplimiento, lo cual constituye la finalidad última de toda obligación. El vínculo es sólo un orden de cooperación, formador de una unidad que no se agota en la suma de los elementos que lo componen. El vínculo pasa a tener sentido propio, diferente del que asumiría si se tratase de una mera suma de sus partes, de un compuesto de derechos, deberes y pretensiones, obligaciones, acciones y excepciones. Considerado como un todo, el vínculo obligatorio no cambia o se modifica con ciertos cambios y modificaciones que sufren las partes. Por este motivo, el cumplimiento de un crédito determinado puede no extinguir, o modificar, la relación jurídica. En otras palabras, incluso habiéndose cumplido el deber principal, la relación jurídica puede subsistir como fundamento de la adquisición (deber de garantía), o a causa de otro deber secundario independiente» (RÉGISapudFIUZA, 2008, p. 206). 
concebida como proceso no es la simple reunión de los factores que la integran, pues «el hazde relaciones es como un todo, y no como una suma» $^{12}$. (PONTES DE MIRANDA, 1984, t. XXVI, § 3.169, 1, p. 283). Además, como advierten Cristiano Chaves e Nelson Rosenvald (2009, p.14):

[...] la concepción contemporánea de la obligación como proceso polarizada al cumplimiento, no es capaz de borrar el mérito de la teoría dualista. A fin de cuentas, a pesar de ser correctamente reconocida como relación jurídica global -bajo el ángulo de su complejidad- la obligación aún sigue siendo apreciada en su acepción estricta -bajo el enfoque de la relación simple- como un vínculo que asegura al acreedor exigir una prestación. Si esta es su esencia, nada mejor que precisar la dicotomía débito/responsabilidad para comprender la médula del proceso obligacional.

Para MenezesCordeiro (2011, p.586), la complejidad intraobligacional traduce la idea de que el vínculo obligatorio comprende «no un simple deber de prestar, simétrico a una pretensión crediticia, sino más bien diversos elementos jurídicos dotados de autonomía suficiente para, de un contenido unitario, hacer una realidad compuesta». Razón por la cual el autor sostiene que en la reconstrucción del contenido de esta no se debe «estudiar y comparar los elementos que la compongan; en lugar de ello, se debe partir del todo hacia sus partes». (FARIAS; ROSENVALD, 2009, p.14)

Por este motivo, Judith Martins-Costa (2003, p.8-9) remarca la necesidad de «descender del plano de las abstracciones al terreno rico y multiforme del concreto», destacando la necesidad de sobrepasar el análisis meramente externo de la relación obligatoria en dirección de

12 Un ejemplo, brindado por el propio Pontes de Miranda(1984, t. XXVI, § 3.169, 1, p. 283), ayudará a aclarar la afirmación: «[...] El concepto, por ejemplo, de relación jurídica de compraventa no es un concepto de relación jurídica a la que corresponda el deber de prestar la cosa, más el de cuidar la cosa hasta su entrega, más el de no descuidar la protección jurídica de la cosa; sin embargo, sí le corresponde el concepto de relación jurídica en la cual todo esto está comprendido».. 
un análisis interno, vale decir, centrado en la noción de cumplimiento ${ }^{13}$, entendido aquí como actuación concreta del programa obligacional, tomando en consideración la concreción de las circunstancias en las que se desarrolla la relación.

Por esta razón, los deberes derivados de la buena fe se ordenan, de esta forma, en grados de intensidad, dependiendo de la categoría de los actos jurídicos a la que se vinculan.(COUTO E SILVA,2006, p. 37)sin ser posible una sistematización uniforme o la elaboración de listas taxativas con una descripción precisa de sus contenidos, dada su tamaña diversidad. (DANTAS JÚNIOR, 2008, p.163)

\section{Conclusión: ¿Deberes laterales o deberes generales de conducta?}

De la digresión anterior, se hace evidente que la terminología empleada por los distintos autores para situar el fenómeno de la relación jurídica obligatoria compleja no es unívoca. Al señalar que toda obligación recibe su carácter distintivo en virtud del deber primario de cumplimiento, Paulo Luis Neto Lôbo(2011, p.74) sostiene que su contenido total comprende deberes de conducta más o menos amplios. El autor destaca, haciendo referencia al pensamiento de Larenz, que existe una variada y extensa terminología para definir aquellos deberes que exceden el propio y estricto deber de prestación, comúnmente denominados secundarios, complementarios, accesorios, conexos, laterales o anexos ${ }^{14}$.

13 Los autores que sostienen que la realidad actual requiere un análisis "ya no centrada en el método tradicional y que concibe la relación obligatoria sólo como un vínculo estructurado sobre dos polos, vinculados por los derechos y deberes correlativos, es decir, dirigida a la descripción de sus elementos constitutivos, considerados in abstracto: los sujetos (acreedor y deudor), el objeto (la prestación, el dar, el hacer o no hacer), los requisitos legales y los elementos accidentales, cuando se hagan presentes» (TEPEDINO; BARBOSA; MORAES, 2004, p. 493).

14 El autor prefiere denominar «accesorias» las obligaciones no autónomas que existen en función de la obligación principal, citando como ejemplos la fianza, la garantía por evicción y la responsabilidad por vicios del producto o del servicio (LÔBO, 2011, p. 74). 
Si al inicio de la elaboración de esta teoría, la concepción clásica de estos deberes de conducta sólo los percibía como deberes derivados del deber primario de cumplimiento e imputables sólo al deudor, la evolución del derecho y, en especial, la metodología del derecho civil constitucional que viene siendo empleada en el ordenamiento brasileño en las últimas dos décadas, elevó algunos de estos deberes al estatus de deberes generales de conducta, en la medida en que se imponen tanto al deudor como al acreedor y, en determinadas circunstancias, a terceros. Sobre este tema, Paulo LuizNettoLôbo2011, p.74) explica que:

Estos deberes no derivan de la relación jurídica obligatoria, y mucho menos del deber de cumplimiento; se ubican por encima de ambos, tanto como límites externos o negativos, cuanto como límites internos o positivos. Derivan directamente de los principios normativos y se irradian sobre la relación jurídica obligatoria y sus efectos, conformando y determinando, de manera contundente, tanto el débito como el crédito. Los deberes generales de conducta exigen la interpretación de sus efectos y alcances directamente coordinada con los principios de los cuales derivan. La comprensión de los primeros implica la de los segundos [...] Los deberes generales de conducta, aunque incidan directamente en las relaciones obligatorias, independientemente de la manifestación de voluntad de los participantes, necesitan la concreción de su contenido, en cada relación, considerando el ambiente social y las dimensiones del tiempo y del espacio de su observancia o aplicación. Esa es su característica, razón por la cual no son susceptibles al proceso tradicional de subsunción del hecho a la norma jurídica.

Para el referido autor, en el sistema jurídico brasileño sería posible definir como deber general de conducta (a) el deber de buena fe objetiva en las obligaciones; (b) el deber de realización de la función social de las obligaciones; (c) el deber de equivalencia material de las prestaciones; (d) el deber de equidad; (e) el deber de informar y (f) el deber de cooperar. Se trata de una postura innovadora en nuestra experiencia jurídica, dado que los autores nacionales suelen negar autonomía propia a los deberes de cooperación e información, ubicándolos en el mismo espacio de la buena fe. 
Paulo LuizNettoLôbo(2011, p.100-102) explica que el derecho a la información y el correlativo deber de informar «tiene raíz histórica en la buena fe, pero adquirieron autonomía propia, ante la tendencia creciente del Estado Social de protección o tutela jurídica de los actores vulnerables de la relaciones jurídicas obligatorias».

En el Código de Defensa del Consumidor Brasileño se encontró el sustrato para su desarrollo, respaldado en los requisitos de adecuación, suficiencia y veracidad. La adecuación no se refiere sólo al contenido de la información, sino también a la forma de difusión (v.g. los medios de comunicación utilizados); mientras tanto la suficiencia se relaciona con la completitud, vale decir, el carácter integral de la información sin la omisión de referencias desventajosas para el proveedor del producto o servicio, como por ejemplo, eventuales consecuencias dañosas de su utilización.

Además, se exige que la información corresponda a las características reales del producto o servicio y que sea conocible, es decir, el consumidor necesita poder comprender la información que le está siendo puesta a disposición, no siendo suficiente para la eficacia del negocio el simple consentimiento, una vez que este se ubica en el plano de validez y no en el plano de la producción de los efectos deseados por las partes.

Asimismo, en defensa de la autonomía en relación al deber general de buena fe, Paulo Lôbo(2011, p.94-95) remarca que el deber de cooperación encuentra su fundamento en el principio constitucional de solidaridad, razón por la cual no se limita al espacio de la relación interindividual, sobrepasando la cualificación de «deber lateral» de conducta, por lo que no debe ser visto como mero efecto secundario de los deberes accesorios, en atención al compromiso valorativo del texto constitucional.

La categoría de los «deberes generales de conducta» no fue elaborada para restar importancia a la evolución doctrinaria que refinó la noción de la obligación como proceso, un todo orgánico dividido en deberes principales, secundarios y laterales. De esta forma, se presenta 
como un paso más de este desarrollo doctrinario, trascendiendo la relación jurídica obligatoria, con reflejos importantes en el campo de la responsabilidad civil, conforme trataremos más adelante.

Esta propuesta de analizar la relación obligatoria buscando especializar otras categorías además de la buena fe, también sirve para reflexionar sobre la omnipresencia de ella en las obras que tratan de la materia. Estamos en un momento en el cual ya se ha alcanzado madurez para refinar dicha categoría, buscando nuevos desarrollos en interés del cumplimiento óptimo.

No obstante, debemos hacer una advertencia. Los conceptos de «deber lateral» y «deber general de conducta» no son excluyentes y deben coexistir en el sistema como instrumentos útiles a la agenda del derecho civil constitucional. Un ejemplo ayudará a la comprensión de dicha afirmación. No todo deber de informar debe ser elevado a la condición de deber general de conducta, pues es posible encontrar en el Código Civil Brasileño diversas situaciones en las que el derecho a la información es tratado como un mero deber accesorio de la prestación obligacional (v.g. arts. $569^{15}, 686^{16}$ y $864^{17}$ ).

Es importante tener en cuenta que los deberes generales de conducta, vinculados directamente a los principios, sobrepasan la función estructural de auxiliares del cumplimiento. (LEONARDO, 2005, p.104105). Al mismo tiempo, actúan como fuente y límite de conformación en el ejercicio de distintas posiciones jurídicas. (CATALAN, 2011, p.141). Finalmente, como consecuencia del marco teórico aquí adoptado, se puede afirmar que "quien contrata ya no contrata sólo lo que contrata», (FACHIN, 2008, p.458) razón por la cual es posible sostener que «aunque ignorados por los contratantes, los deberes bajo análisis pueden asumir

\footnotetext{
15 Art. 566 del Cód. Civ. Br.: El arrendatario está obligado:“[...] III. A informar al arrendador las perturbaciones de terceros, que pretendan estar fundadas en derecho."

16 Art. 686 del Cód. Civ. Br.: "La revocación del mandato, notificada sólo al mandatario, no puede oponerse a los terceros que, ignorándola, tratasen con él de buena fe; pero quedan a salvo al mandante las acciones que le pudieran corresponder contra el mandante".

17 Art. 864 del Cód. Civ. Br.: "En la medida de lo posible, el gestor comunicará al dueño del negocio la gestión que asumió, quien debe esperar la respuesta, si de la espera no resultase algún peligro".
} 
una dimensión negativa, impidiendo la invasión arbitraria de la intimidad; o positiva, al facilitar, por ejemplo, el cumplimiento». (CATALAN, 2011, p.141).

El deber de realización de la función social de las obligaciones actúa como límite positivo que conforma todo el tráfico jurídico entre los particulares, aunque no esté explícito en el texto de la Constitución brasileña. Expresa el comando de que los intereses individuales deben ser ejercidos sin entrar en conflicto con los intereses sociales, siempre que estos se presenten.

Hay quien identifica en dicho deber sólo una mitigación del clásico principio de la relatividad de los efectos del contrato, cuya aplicación estaría sujeta a situaciones en las que terceros estuviesen siendo perjudicados por aquello que fue pactado. En esta perspectiva, la función social estaría relacionada a consecuencias meramente externas, sin surtir efecto alguno en la relación directa entre los contratantes ${ }^{18}$.

Sin embargo, preferimos afiliarnos a la corriente que busca la funcionalización del principio de solidaridad a través del deber de realizar la función social del contrato, perspectiva que prescribe compromisos en pro de la comunidad, no sólo a través de la imposición de límites, sino, en la mayoría de los casos, a través de la restricción de la propia posibilidad de contratar, con reflejos en la responsabilidad contractual ${ }^{19}$.

Cada uno de los deberes generales aquí mencionados merecería, por sí mismo, un estudio específico, lo que sobrepasa los objetivos de este trabajo. Sólo hemos tratado de contribuir al debate y reflexión sobre

18 Humberto Theodoro Júnior (2003, p. 37-40), quien sostiene que no es razonable «presumir la desviación de la función social, cuando la deslealtad de un contratante perjudique sólo los intereses de otro». La solución para los casos de abuso interindividual quedaría adscrita al campo de la buena fe objetiva; de manera que el único legitimado para buscar tutela jurídica del Estado sería el damnificado.

19 En este sentido, el parágrafo único del art. 2035 del Cód. Civ. Br., norma de orden público, prescribe que «ninguna convención prevalecerá si contraría preceptos de orden público, tales como los establecidos por este Código para asegurar la función social de la propiedad y de los contratos». Este dispositivo se aplica incluso a los actos jurídicos constituidos antes de la entrada en vigencia del Cód. Civ. Br. de 2002, en lo concerniente a sus efectos, producidos luego de la entrada en vigencia de este. 
los temas fundamentales para un modelo de interpretación que cada vez más con mayor frecuencia utiliza conceptos abiertos en la búsqueda de fundamentación para hacer frente a problemas cada vez más complejos y a casos que atraviesan nuestro día a día forense.

\section{Referencias}

BECKER, Anelise. Elementos para uma teoria unitária da responsabilidade civil. In: NERY JUNIOR, Nelson; NERY, Rosa Maria de Andrade (Org.). Responsabilidade civil: doutrinas essenciais, teoria geral. São Paulo: Revista dos Tribunais, 2010. v. I. p. 365.

CATALAN, Marcos Jorge. Descumprimento contatual. Curitiba: Juruá, 2010.

CATÃO, Adrualdo de Lima. Considerações acerca dos conceitos fundamentais da teoria geral do processo: direito subjetivo, pretensão, ação material, pretensão à tutela jurídica e remédio jurídico processual. Jus Navigandi, Teresina, ano 7, n. 60, nov. 2002. Disponível em: <http:// jus2.uol.com.br/doutrina/texto.asp?id=3483>. Acesso em: 11 ago. 2009.

CORDEIRO, António Manuel da Rocha Menezes. Da boa-fé no direito civil. Coimbra: Almedina, 2011.

COUTO E SILVA, Clóvis. A obrigação como processo. Rio de Janeiro: FGV, 2006.

DANTAS JUNIOR, Aldemiro Rezende. Teoria dos atos próprios no princípio da boa-fé. Curitiba: Juruá, 2008.

FACHIN, Luiz Edson. Estatuto Jurídico do Patrimônio Mínimo. Rio de Janeiro: Renovar, 2006.

FARIAS, Cristiano Chaves de; ROSENVALD, Nelson. Direito das obrigações. 4. ed. Rio de Janeiro: Lumen Juris, 2009.

Fiuza, Ricardo. Código Civil comentado. 6. ed. São Paulo: Saraiva, 2008. 
GAGLIANO, Pablo Stolze; PAMPLONA FILHO, Rodolfo. Novo curso de direito civil: contratos. São Paulo: Saraiva, 2005. v. IV.

GOMES, Orlando. Obrigações. 16. ed. Rio de Janeiro: Forense, 2004. GONÇALVES, Carlos Roberto. Direito civil brasileiro: teoria geral das obrigações. 6. ed. São Paulo: Saraiva, 2009. v. II.

HAICAL, Gustavo Luís da Cruz. O inadimplemento pelo descumprimento exclusivo de dever lateral advindo da boa-fé objetiva. In: MOTA, Maurício; $\mathrm{KLOH}$, Gustavo. Transformações contemporâneas do direito das obrigações. Rio de Janeiro: Elsevier, 2011. p. 45-84.

LEONARDO, Rodrigo Xavier. A teoria das redes contratuais e a função social dos contratos: reflexões a partir de uma recente decisão do Superior Tribunal de Justiça. Revista dos Tribunais, São Paulo, v. 94, n. 832, p. 100-111, fev. 2005.

LÔBO, Paulo Luiz Netto. Direito civil: obrigações. São Paulo: Saraiva, 2011.

MARTINS-COSTA, Judith. Comentários ao novo Código Civil. Do direito das obrigações - do adimplemento e da extinção das obrigações. In: TEIXEIRA, Sálvio de Figueiredo (Coord.). Rio de Janeiro: Forense, 2003. v. V. t. I.

MELLO, Marcos Bernardes de. Teoria do fato jurídico: plano da existência. 14. ed. São Paulo: Saraiva, 2007.

MONTEIRO, Washington Barros. Curso de direito civil. São Paulo: Saraiva, 2003. v. 4.

NANNI, Giovanni Ettore (Coord.). Temas relevantes do direito civil contemporâneo. São Paulo: Atlas, 2008.

NORONHA, Fernando. Direito das obrigações. São Paulo: Saraiva, 2004. v. 1. p. 79-81.

PEREIRA, Caio Mário da Silva. Instituições de direito civil: teoria geral das obrigações. 22. ed. Rio de Janeiro: Forense, 2009. v. II. 
PONTES DE MIRANDA, Francisco Cavalcanti. Tratado das ações. 2. ed. São Paulo: RT, 1972. t. I.

. Tratado de Direito Privado. São Paulo: Revista dos Tribunais, 1984. t. XXVI, § 3.102. p. 12.

RIZZARDO, Arnaldo. Direito das obrigações. Rio de Janeiro: Forense, 2006.

RODRIGUES, Sílvio. Direito civil: parte geral das obrigações. 30. ed. São Paulo: Saraiva, 2002. v. 2.

SAVI, Sérgio. Inadimplemento das obrigações, mora e perdas e danos. In: TEPEDINO, Gustavo (Coord.). Obrigações: estudos na perspectiva civil-constitucional. Rio de Janeiro: Renovar, 2005. p. 489-512.

TEPEDINO, Gustavo; BARBOSA, Heloisa Helena; MORAES, Maria Celina Bondin de. Código Civil interpretado: parte geral e obrigações. Rio de Janeiro: Renovar, 2004.

TEPEDINO, Gustavo; FACHIN, Luiz Edson (Coord.). O direito e o tempo: embates jurídicos e utopias contemporâneas. Rio de Janeiro: Renovar, 2008.

TOMASETTI JUNIOR, Alcides, As relações de consumo em sentido amplo na dogmática das obrigações e dos contratos. Revista de Direito do Consumidor, São Paulo, n. 13, p. 12-17, jun./mar. 1995.

VARELA, J. M. Antunes. Direito das obrigações. Rio de Janeiro: Forense, 1977.

Recebido em: 24/07/2015

Aprovado em: 22/09/2015 